\title{
Clinical Characteristics and Postoperative Outcomes of Patients Presenting With Upper Gastrointestinal Tract Crohn Disease
}

\author{
Joon Suk Moon ${ }^{1}$, Jong Lyul Lee ${ }^{1}$, Chang Sik Yu ${ }^{1}$, Seok-Byung Lim ${ }^{1}$ In Ja Park ${ }^{1}$, Yong Sik Yoon ${ }^{1}$, \\ Chan Wook Kim ${ }^{1}$, Suk-Kyun Yang ${ }^{2}$, Byong Duk Ye², Sang Hyoung Park ${ }^{2}$, Hassan Abdullah Alsaleem ${ }^{1,3}$, \\ Jin Cheon $\mathrm{Kim}^{1}$ \\ ${ }^{1}$ Department of Surgery, Asan Medical Center, University of Ulsan College of Medicine, Seoul; '2Department of Gastroenterology, Asan \\ Medical Center, University of Ulsan College of Medicine, Seoul, Korea; ${ }^{3}$ Department of Surgery, College of Medicine, Imam Abdulrahman Bin \\ Faisal University, Dammam, Saudi Arabia
}

Purpose: Upper gastrointestinal (GI) tract involvement in Crohn disease (CD) is rare and effectiveness of surgical treatment is limited. The aim of this study was to evaluate characteristics and surgical outcomes of upper GI CD.

Methods: Medical records of 811 patients who underwent intestinal surgery for CD between January 2006 and December 2015 at a single institution were reviewed. Upper GI CD was defined by involvement of the stomach to the fourth portion of duodenum, with or without concomitant small/large bowel CD involvement according to a modification of the Montreal classification.

Results: We identified 24 patients ( 21 males, 3 females) who underwent surgery for upper GI CD. The mean age at diagnosis was $27 \pm 12$ years, the mean age at surgery was $33 \pm 11$ years, and the mean duration of CD was $73.6 \pm 56.6$ months. Fifteen patients $(62.5 \%)$ had history of previous perianal surgery. Ten patients $(41.7 \%)$ had duodenal or gastric stricture and 14 patients $(58.3 \%)$ had penetrating fistula; patients with fistula were significantly more likely to develop complications $(57.1 \%$ vs. $20.0 \%, \mathrm{P}=0.035)$. One patient with stricture had surgical recurrence. In seven patients with fistula, fistula was related to previous anastomosis. Patients with fistula had significantly longer hospital stays than those with stricture ( 16 days vs. 11 days, $\mathrm{P}=0.01$ ).

Conclusion: Upper GI CD is rare among CD types (2.96\%). In patients with upper GI CD, penetrating fistula was associated with longer hospital stay and more complications.

Keywords: Crohn disease; Upper gastrointestinal tract; Incidence; Treatment; Outcome

\section{INTRODUCTION}

Crohn disease $(\mathrm{CD})$ is an inflammatory condition, resulting from stricturing and penetrating complications that can affect any site

Received: Jul 3,2019 - Revised: Oct 13,2019 - Accepted: Oct 16, 2019 Correspondence to: Jong Lyul Lee, M.D.

Department of Surgery, Asan Medical Center, University of Ulsan College of Medicine, 88 Olympic-ro 43-gil, Songpa-gu, Seoul 05505, Korea

Tel: +82-2-3010-1732, Fax: +82-2-474-6027

E-mail: iamleejong@amc.seoul.kr

ORCID: https://orcid.org/0000-0002-5878-8000

(C) 2020 The Korean Society of Coloproctology

This is an open-access article distributed under the terms of the Creative Commons Attribution NonCommercial License (https://creativecommons.org/licenses/by-nc/4.0) which permits unrestricted noncommercial use, distribution, and reproduction in any medium, provided the original work is properly cited. along the gastrointestinal (GI) tract $[1,2]$. The most common CD site is the terminal ileum with or without the ileocecal valve, cecum, or proximal ascending colon $[3,4]$, while involvement of the upper GI tract, stomach, and duodenum is rare [5-7]. Since the first reported case of upper GI tract involvement by Gottlieb [8] in 1937, upper GI CD has only been found in $0.3 \%-5 \%$ of patients with $\mathrm{CD}[7,9-13]$.

$\mathrm{CD}$ is divided into 4 types according to location: ileal (L1), colonic (L2), ileocolonic (L3), and isolated upper disease (L4) [2, 14]. From the Montreal revision of the Vienna classification, L4 is defined as upper GI involvement of CD with or without concomitant L1-3 disease [2]. L4 remains poorly understood due to its rarity. While surgery has been suggested as a safe option for patients with intractable duodenal CD [10], surgeries are still per- 
formed according to the surgeons' experience due to the lack of documented studies and guidance.

The most frequent symptoms in patients with upper GI CD are related to obstruction, such as early satiety, nausea, distension, or vomiting $[11,15]$. Although most symptoms are associated with obstruction, some patients experience frequent diarrhea or weight loss related to gastro- or duodeno-colic fistula. Depending on the type of $\mathrm{CD}$ involvement, different treatment strategies can be pursued.

The purpose of the current study is to evaluate the clinical characteristics and surgical outcomes of upper GI CD and to compare those of upper GI CD and CD at other sites.

\section{METHODS}

\section{Patient characteristics}

We retrospectively evaluated medical records of patients who underwent intestinal surgery for CD at Asan Medical Center, Seoul, Korea between January 2006 and December 2015. Patients were included if they had undergone bowel resection, strictureplasty, or bypass surgery for $\mathrm{CD}$ during the study period and were 16 years of age or older at the time of surgery. Patients were excluded if surgery was only open biopsy, stoma formation, or restoration of stoma; if there was a concurrent or prior history of other malignancies; or if $\mathrm{CD}$ could not clarify the location due to ambiguous description or absence of location information on medical record. The following variables from the medical records of the study cohort were collected: demographic characteristics (sex, age at diagnosis and at surgery, duration and follow-up of CD, family history, history of smoking, previous perianal and abdominal surgery); preoperative characteristics (indication for surgery; Montreal classification; and preoperative medications including steroids, immunomodulators, and anti-tumor necrosis factor alpha); operative details (operative approach; timing of surgery including whether the procedure was elective or emergency; methods of anastomosis; and anastomosis shapes including side-to-side, endto-side, or end-to-end); and postoperative outcomes (duration of postoperative hospital stay, clinical recurrence and surgical recurrence of $\mathrm{CD}$, and postoperative complications by postoperative day 30 ).

\section{Ethical standards}

The study protocol was approved by the Institutional Review Board of the Asan Medical Center (IRB No. 2019-0428), and the study was performed in accordance with the Declaration of Helsinki.

\section{Definition and classification of upper GI involvement of CD} Upper GI CD was defined as L4 according to the Montreal classification and gastric or duodenal fistula related to anastomosis at other sites. For subgroup analysis, patients with upper GI CD involvement were classified as either stricturing group or penetrating group according to the indication of surgery. Other site $\mathrm{CD}$ was defined as any kind of $\mathrm{CD}$ involvement apart from upper GI CD.

\section{Assessment and treatment of CD}

$\mathrm{CD}$ location was assessed based on pathological, intraoperative, and imaging findings using a small bowel series (SBS), computed tomography enterography (CTE), magnetic resonance imaging (MRI), and colonoscopy. Medical treatment of $\mathrm{CD}$ was based on a step-up approach, and more potent therapies were added if and when patients became unresponsive to first-line or less toxic agents, as mentioned in a previous report from our institution [4]. During medical treatment, the gastroenterologist consulted with specialized colorectal surgeons when considering surgery.

\section{Measurement of postoperative outcomes}

Postoperative complications were defined as grade $2 \mathrm{~A}$ or higher on the Clavien-Dindo classification after surgery [16]. Postoperative complications were classified as noninfectious or infectious. Non-infectious complications included postoperative ileus; bleeding at the anastomosis site or an intraabdominal hematoma that required transfusion, pig-tail drainage or similar intervention, surgery, or close monitoring due to massive hematochezia ( $>3$ times per a day); a thromboembolic event such as deep vein thrombosis or pulmonary thromboembolism; pleural effusion; and organ dysfunction. Infectious complications included intraabdominal sepsis (anastomotic leakage and intraabdominal abscess determined by an obvious change in drainage or abdominopelvic computed tomography), entero-cutaneous fistula, wound infection, and extra-abdominal infections (sepsis and urinary and respiratory tract infections).

Recurrences were divided into clinical and surgical recurrence. Clinical recurrence was defined as a definite change in imaging studies (SBS, CTE, or MRI) or colonoscopy following the onset of symptoms in a patient (e.g., any type of fistula with an abscess on imaging or a stricture or an ulcer that was difficult to pass by colonoscopy). Surgical recurrence was defined as any repeated surgery on any section of the bowel for pathologically confirmed CD. Repeated operations for pathologically confirmed anastomotic disease, including cases in which the small bowel was diseased at the anastomosis or the stoma site, were also defined as surgical recurrences.

\section{Statistical analysis}

Discrete variables including demographic and preoperative characteristics, operative methods, and operative details were analyzed using the chi-squared test comparing upper GI CD with other sites. Continuous variables including age at surgery, hospital stay duration, and duration of follow-up after surgery were compared using unpaired Student t-test or the Mann-Whitney U-test as appropriate. Statistical significance was defined as $\mathrm{P}<0.05$, and all statistical analyses were performed using IBM SPSS Statistics ver. 21.0 (IBM Corp., Armonk, NY, USA). 


\section{RESULTS}

\section{Clinical characteristics of patients}

Of 811 patients, 339 patients (41.8\%) had ileal involvement, 54 patients $(6.7 \%)$ had colonic involvement, and 387 patients $(47.7 \%)$ had ileo-colonic involvement. Only 24 patients $(2.96 \%)$ met the criteria for upper GI CD. The ratio of males to females in the study cohort was 7:1. The mean ages at diagnosis and at operation in the upper GI CD patients were $27 \pm 11.8$ years and $32.8 \pm 10.8$ years, respectively. Patients with upper GI CD had more smoking history (45.8\% ex-smoker and $12.5 \%$ current smoker) and perianal surgery $(62.5 \%)$ than patients with $\mathrm{CD}$ at other sites $(24.3 \%$ ex-smoker, $9.5 \%$ current smoker, $\mathrm{P}=0.035$ and $40.6 \%$ perianal surgery, $\mathrm{P}=0.036)$. Among the 24 patients with upper $\mathrm{GI} C D$, the proportion of concomitant other site involvement was lower in L1 and higher in L2 and L3 (16.7\% L1, 16.7\% L2, and 66.7\% L3, P = $0.015)$ compared with the proportion of CD at other sites. Variables that did not differ significantly between these 2 groups included age at diagnosis and operation, sex, duration of disease, follow-up duration, body mass index at the time of operation, family history of CD, age and disease behavior by Montreal classification, and prescribed medication (Table 1).

All but one patient with upper GI CD underwent open surgery, while $21.3 \%$ of patients with $\mathrm{CD}$ at other sites underwent laparoscopic surgery $(P=0.008)$. All patients with upper GI CD underwent hand-sewn anastomosis, and more patients with upper GI CD underwent hand-sewn anastomosis for concomitant other site $\mathrm{CD}$ than patients with $\mathrm{CD}$ at other sites $(16.7 \%$ vs. $3.0 \%, \mathrm{P}=$ 0.006). Four patients with upper GI CD received ileostomy for ileocolic involvement of $\mathrm{CD}$. The rate of emergency operation and anastomosis types were not significantly different between patients with upper GI CD and patients with CD at other sites (Table 2).

\section{Postoperative outcomes of patients}

Patients with upper GI CD required more packed red blood cell transfusion (7.04 \pm 18.24 units vs. $1.64 \pm 3.84$ units, $\mathrm{P}=0.001)$, longer operation time $(196 \pm 68$ minutes vs. $158 \pm 64$ minutes, $\mathrm{P}=$ 0.013 ), and longer hospital stays than patients with $\mathrm{CD}$ at other sites $(27.5 \pm 49.8$ days vs. $12.8 \pm 13.0$ days, $\mathrm{P}=0.001)$. In terms of complications, patients with upper GI CD experienced more anastomotic leakage $(16.7 \%$ vs. $3.6 \%, \mathrm{P}=0.012)$ and more postoperative ileus $(12.5 \%$ vs. $2.8 \%, \mathrm{P}=0.034)$. More patients with upper GI CD experienced clinical and surgical recurrence compared with patients with $\mathrm{CD}$ at other sites (clinical recurrence: $62.5 \%$ vs. $59.3 \%, \mathrm{P}=0.001$; surgical recurrence: $16.7 \%$ vs. $11.4 \%, \mathrm{P}=0.001$ ). There was no significant difference in mean time to clinical and surgical difference between the upper GI CD group and the other site CD group (Tables 3, 4).

In the subgroup analysis, stricturing was indicated in 10 patients (45\%) and penetrating was diagnosed 14 patients (55\%). Stricturing was identified in gastric (6 patients, 66.7\%) and duodenal (4 patients, $33.3 \%$ ) locations. The penetrating group included fistula
Table 1. Demographic characteristics of patients with CD in the upper GI tract and other sites

\begin{tabular}{|c|c|c|c|}
\hline Variable & $\begin{array}{l}\text { Upper GI CD } \\
\quad(n=24)\end{array}$ & $\begin{array}{l}\text { Other site CD } \\
(\mathrm{n}=787)\end{array}$ & P-value \\
\hline Age at diagnosis (yr) & $27 \pm 12$ & $26 \pm 10$ & 0.75 \\
\hline Age at operation (yr) & $33 \pm 11$ & $32 \pm 10$ & 0.61 \\
\hline Sex, female: male & $3(12.5): 21$ (87.5) & $233(29.6): 554(70.4)$ & 0.07 \\
\hline Duration of disease (mo) & $73.6 \pm 56.6$ & $69.7 \pm 61.1$ & 0.87 \\
\hline Follow-up duration (mo) & $147.1 \pm 59.7$ & $145.1 \pm 69.5$ & 0.88 \\
\hline $\begin{array}{c}\text { Body mass index at } \\
\text { operation }\left(\mathrm{kg} / \mathrm{m}^{2}\right)\end{array}$ & $17.76 \pm 2.27$ & $18.55 \pm 3.10$ & 0.11 \\
\hline Hospital stay (day) & $36.6 \pm 58.4$ & $19.4 \pm 16.6$ & $0.001^{*}$ \\
\hline Family history of $C D$, yes & $0(0)$ & $24(3.0)$ & 0.48 \\
\hline History of smoking & & & $0.035^{*}$ \\
\hline None & $10(41.7)$ & $521(66.2)$ & \\
\hline Ex-smoker & $11(45.8)$ & $191(24.3)$ & \\
\hline Current smoker & $3(12.5)$ & $75(9.5)$ & \\
\hline $\begin{array}{l}\text { Previous abdominal } \\
\text { surgery, yes }\end{array}$ & $11(45.8)$ & $266(33.7)$ & 0.45 \\
\hline $\begin{array}{l}\text { Previous perianal surgery, } \\
\text { yes }\end{array}$ & $15(62.5)$ & $319(40.6)$ & $0.036^{*}$ \\
\hline History of fistula-in-ano & & & 0.06 \\
\hline Yes & $17(70.8)$ & $393(49.9)$ & \\
\hline No & $7(29.2)$ & $394(50.1)$ & \\
\hline \multicolumn{2}{|c|}{ Montreal classification behavior } & & 0.76 \\
\hline $\begin{array}{l}\text { Nonstricturing, } \\
\text { nonpenetrating (B1) }\end{array}$ & $2(8.3)$ & $42(5.4)$ & \\
\hline Stricturing (B2) & $10(41.7)$ & $270(34.3)$ & \\
\hline Penetrating (B3) & $12(50.0)$ & $475(60.3)$ & \\
\hline \multicolumn{2}{|c|}{ Montreal classification location } & & $0.015^{\star}$ \\
\hline Ileocolic (L1) & $4(16.7)^{\mathrm{a}}$ & $346(43.9)$ & \\
\hline Colic (L2) & $4(16.7)^{\mathrm{a}}$ & $54(6.9)$ & \\
\hline Ileal (L3) & $16(66.7)^{\mathrm{a}}$ & $387(49.2)$ & \\
\hline \multicolumn{4}{|l|}{ Medication } \\
\hline $\begin{array}{l}\text { 5-Amino-salicylic acid or } \\
\text { no medication }\end{array}$ & $8(33.3)$ & $339(43.1)$ & 0.21 \\
\hline IMM & $10(41.7)$ & $243(30.9)$ & 0.27 \\
\hline Anti-TNF-a & $1(4.2)$ & $48(6.1)$ & 0.57 \\
\hline Steroid & $0(0)$ & $42(5.3)$ & 0.63 \\
\hline IMM+TNF & $3(12.5)$ & $54(6.9)$ & 0.24 \\
\hline IMM+steroid & $2(8.3)$ & $41(5.2)$ & 0.37 \\
\hline Steroid+TNF & $0(0)$ & $8(1.0)$ & 0.79 \\
\hline All combination & $0(0)$ & $12(1.5)$ & 0.70 \\
\hline
\end{tabular}

Values are presented as mean \pm standard deviation or number $(\%)$.

$\mathrm{CD}$, Crohn disease; Gl, gastrointestinal; IMM, immunomodulatory; TNF, tumor necrosis factor.

${ }^{*} \mathrm{P}<0.05$, significant differences.

This number and proportion included other site Crohn disease with upper gastrointestinal Crohn disease. 


\section{Coloproctology Joon Suk Moon, et al.}

Table 2. Operative details of patients with CD in the upper GI tract and other sites

\begin{tabular}{|c|c|c|c|}
\hline Variable & $\begin{array}{l}\text { Upper GI CD } \\
\qquad(n=24)\end{array}$ & $\begin{array}{l}\text { Other site CD } \\
\quad(n=787)\end{array}$ & P-value \\
\hline Emergency operation, yes & $1(4.2)$ & $70(8.9)$ & 0.710 \\
\hline Operative approach & & & $0.008^{*}$ \\
\hline Open & 23 (95.8) & $619(78.7)$ & \\
\hline Laparoscopy & $1(4.2)$ & $168(21.3)$ & \\
\hline Anastomosis method & & & $0.006^{*}$ \\
\hline Hand-sewn & $24(100) / 4(16.7)^{\mathrm{a}}$ & $23(3.0)$ & \\
\hline Stapled & $0(0) / 16(66.7)^{\mathrm{a}}$ & $639(82.0)$ & \\
\hline Stoma formation & $0(0) / 4(16.7)^{\mathrm{a}}$ & $117(15.0)$ & \\
\hline Anastomosis type & & & 0.580 \\
\hline $\begin{array}{l}\text { Side-to-side, functional end-to- } \\
\text { end }\end{array}$ & $13(54.2) / 17(70.8)^{a}$ & $565(72.5)$ & \\
\hline End-to-side & $0(0) / 1(4.2)^{\mathrm{a}}$ & $61(7.8)$ & \\
\hline End-to-end & $11(45.8) / 2(8.3)^{\mathrm{a}}$ & $36(4.6)$ & \\
\hline Stoma formation & $0(0) / 4(16.7)^{\mathrm{a}}$ & $117(15.0)$ & \\
\hline
\end{tabular}

Values are presented as number (\%).

$\mathrm{CD}$, Crohn disease; Gl, gastrointestinal.

${ }^{*} \mathrm{P}<0.05$, significant differences.

aThe results show the anastomosis method and type of the concomitant surgery for other site $C D$.

Table 3. Operative outcomes of patients with CD in the upper GI tract and other sites

\begin{tabular}{lccl}
\hline Variable & $\begin{array}{c}\text { Upper GI CD } \\
(\mathrm{n}=24)\end{array}$ & $\begin{array}{c}\text { Other site CD } \\
(\mathrm{n}=787)\end{array}$ & P-value \\
\hline Postoperative pRBC transfusion (unit) & $7.04 \pm 18.24$ & $1.64 \pm 3.84$ & $0.001^{*}$ \\
Operative time (min) & $196 \pm 68$ & $158 \pm 64$ & $0.013^{*}$ \\
Hospital stay after surgery (day) & $27.5 \pm 49.8$ & $12.8 \pm 13.0$ & $0.001^{*}$ \\
Total complications & $10(41.7)$ & $193(24.6)$ & 0.16 \\
$\quad$ Intra-abdominal infection & $5(20.8)$ & $72(9.2)$ & 0.07 \\
Bleeding & $0(0)$ & $23(2.9)$ & 0.72 \\
Wound & $2(8.3)$ & $70(8.9)$ & 0.64 \\
Anastomotic leak & $4(16.7)$ & $28(3.6)$ & $0.012^{*}$ \\
Postoperative ileus & $3(12.5)$ & $22(2.8)$ & $0.034^{*}$ \\
Entero-cutaneous fistula & $0(0)$ & $4(0.5)$ & 0.89 \\
Clinical recurrence, yes & $15(62.5)$ & $467(59.3)$ & $0.001^{*}$ \\
Mean time to clinical recurrence (mo) & $39 \pm 23$ & $35 \pm 27$ & 0.54 \\
Surgical recurrence, yes & $4(16.7)$ & $90(11.4)$ & $0.001^{*}$ \\
Mean time to surgical recurrence (mo) & $77 \pm 19$ & $49 \pm 34$ & 0.055 \\
\hline
\end{tabular}

Values are presented as mean \pm standard deviation or number (\%).

$\mathrm{CD}$, Crohn disease; Gl, gastrointestinal; pRBC, packed red blood cell.

${ }^{*} \mathrm{P}<0.05$, significant differences.

related to previous anastomosis (7 patients, $54.5 \%$ ), gastric fistula (2 patients, $45.5 \%$ ), and duodenal fistula (5 patients, $45.5 \%$ ) (Fig.
Table 4. Postoperative hospital stay and complications of patients with $\mathrm{CD}$ in the upper GI tract and other sites

\begin{tabular}{lccl}
\hline Variable & $\begin{array}{c}\text { Stricture } \\
(\mathrm{n}=10)\end{array}$ & $\begin{array}{c}\text { Penetrating } \\
(\mathrm{n}=14)\end{array}$ & P-value \\
\hline Hospital stay after surgery (day) & $11(8-15)$ & $16(12-30)$ & $0.01^{*}$ \\
Overall complication & $2(20.0)$ & $8(57.1)$ & $0.035^{\star}$ \\
$\quad$ Intraabdominal abscess & 0 & $4(28.6)$ & 0.55 \\
Wound & 0 & $2(27.3)$ & 0.22 \\
Anastomotic leak & $2(22.2)$ & $1(9.1)$ & 0.58 \\
Postoperative ileus & $1(11.1)$ & $1(9.1)$ & 0.71 \\
\hline
\end{tabular}

Values are presented as median (interquartile range) or number (\%).

${ }^{*} \mathrm{P}<0.05$, significant differences.

1). Though not statistically significant, a higher proportion of patients in the penetrating group developed infectious complications such as anastomotic leak than patients in the stricturing group ( $42.9 \%$ vs. $10 \%, \mathrm{P}=0.07$ ). One patient $(10.0 \%)$ in the stricturing group had a surgical complication requiring a second anastomosis procedure. Two patients (20.8\%) with duodenal fistula in the penetrating group needed an additional primary repair procedure with or without feeding jejunostomy (Fig. 1).

\section{DISCUSSION}

The current study investigated clinical characteristics, surgical management, and operative outcomes of patients with upper GI CD. Previous retrospective studies showed a prevalence of $0.3 \%$ $5 \%[7,9-13]$, while the few prospective studies to analyze $\mathrm{CD}$ presentation after esophagogastroduodenoscopy in upper GI CD have suggested a prevalence of $24 \%$ to $56 \%[17,18]$. We found the prevalence of upper GI CD to be $2.96 \%$, in line with other retrospective studies that reported using surgical data [10-13] and endoscopic data [19]. Although the previous prospective studies found quite high prevalence ( $56 \%)$ from endoscopy and endoscopic biopsy [17, 18], the current study showed that the rate of patients who needed surgery was just around $3 \%$. The majority of patients in our study experienced frequent stool passage or diarrhea related to penetrating fistula, especially those related to previous anastomosis (29.2\%), followed by symptoms reported in other studies $[17,20]$ such as nausea, vomiting, and indigestion.

We found that patients with upper GI CD were significantly more likely to be male and to have a history of perianal surgery and smoking than patients with $\mathrm{CD}$ at other sites. Although male dominance of $\mathrm{CD}$ has been previously reported in Korea-unlike the relatively similar sex ratio in Western countries [21-23] — most upper GI CD patients were male but differences in sex were not statistically significant in the multivariate analysis $(\mathrm{P}=0.084)$. One study reported that $\mathrm{CD}$ with perianal disease was associated with a more severe course of disease [24]. In Korea, perianal CD involvement had high prevalence at around 40\%, compared with a prevalence of around $20 \%$ in Western countries $[4,25]$. It is well 


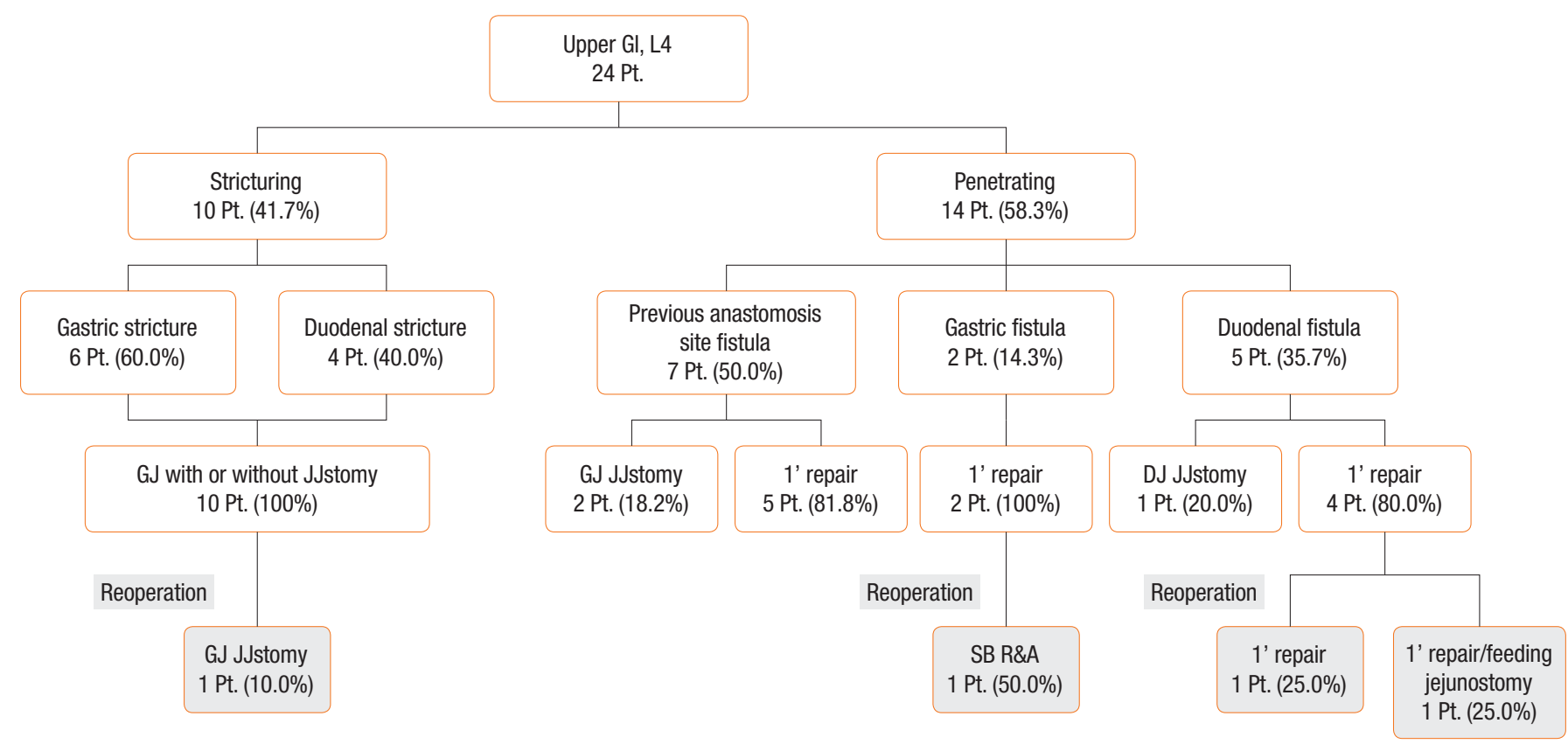

Fig. 1. Classification and operative details of the upper gastrointestinal Crohn disease patients. GI, gastrointestinal; Pt, patient; GJ, gastrojejunostomy; JJstomy, jejunojejunostomy; 1' repair, primary repair; DJ, duodenojejunostomy; SB R\&A, small bowel resection and anastomosis.

known that smoking is associated with $\mathrm{CD}[26,27]$. Considering our findings, smoking cessation and education related to smoking may help prevent the development of upper GI CD.

Options for surgical management of complicated upper GI CD include bypass, resection, or strictureplasty [10]. Unlike the management of $\mathrm{CD}$ in other parts of the GI tract, bypass is favored over resection for upper GI CD [10]. This may be due to the anatomical differences and the complexity of upper GI resection. The results of the current study were similar and all patients with stricturing CD received bypass surgery (78.6\% patients with penetrating CD primary repair and $21.4 \%$ patients with penetrating $\mathrm{CD}$ bypass surgery). Considering the relatively good postoperative results of the current study, surgical procedures should be selected after consideration of the characteristics, location, and behavior of CD. Some studies have found that resection has four times the morbidity of bypass surgery and have insisted that bypass with or without vagotomy and strictureplasty is preferable for the treatment of intractable duodenal CD $[5,10]$. Previous studies have attempted to examine the appropriateness of surgical treatment of duodenal $\mathrm{CD}$, but they have not yet identified the treatment of choice [5]. Although laparoscopic surgery is recently increasing even in CD [28], the current study showed that only one patient with upper GI CD (4.2\%) received laparoscopic surgery due to high rate of reoperation (45.8\%) and complexity of surgery $(100 \%$ concomitant other site $\mathrm{CD})$.

The current study found that patients with upper GI CD required more transfusion, had longer operation time and hospital stays, experienced more anastomotic leak and postoperative ileus, and had higher rates of clinical and surgical recurrences than patients with $\mathrm{CD}$ at other sites, which is in line with other studies [5, 29]. The current study also found that more patients in the penetrating group experienced postoperative complications than did patients in the stricturing group. However, one study revealed that patients with upper GI CD seemed to show an even better outcome regarding development of intestinal fistula (penetrating disease) [5]. Although that study found good outcomes in patients with penetrating fistula, considering the complexity of surgery related to anatomical difficulty of duodenal surgery and needs of more anastomosis in aspect of the anastomosis of the affected bowel sites, appropriate surgery would be needed. Besides, the current study included patients with previous anastomosis site fistula, and these patients did not need reoperation, even primary closure (Fig. 1). Although there was no institutional strategy for primary repair of upper GI fistula, this result implies that fistula related to a previous anastomosis site produced good outcome even in primary closure.

Because this study was retrospective in design, we could not completely control for patient characteristics. However, this study not only assessed upper GI CD, but also other site CD characteristics, surgical methods, and postoperative outcomes. Another limitation of this study was the lack of analysis of endoscopic findings. Nevertheless, the present study is meaningful in identifying the incidence of upper GI CD among patients who underwent intestinal surgery with a relatively larger number than other retrospective studies.

In conclusions, $\mathrm{CD}$ patients with upper GI involvement had low 
prevalence, a relatively low rate of surgical recurrence, and prolonged hospital stays after surgery. The penetrating group had more complications than the stricturing group.

\section{CONFLICT OF INTEREST}

No potential conflict of interest relevant to this article was reported.

\section{REFERENCES}

1. Lock MR, Farmer RG, Fazio VW, Jagelman DG, Lavery IC, Weakley FL. Recurrence and reoperation for Crohn's disease: the role of disease location in prognosis. N Engl J Med 1981;304:1586-8.

2. Satsangi J, Silverberg MS, Vermeire S, Colombel JF. The Montreal classification of inflammatory bowel disease: controversies, consensus, and implications. Gut 2006;55:749-53.

3. Farmer RG, Whelan G, Fazio VW. Long-term follow-up of patients with Crohn's disease: relationship between the clinical pattern and prognosis. Gastroenterology 1985;88:1818-25.

4. Park SH, Yang SK, Park SK, Kim JW, Yang DH, Jung KW, et al. Long-term prognosis of Crohn's disease and its temporal change between 1981 and 2012: a hospital-based cohort study from Korea. Inflamm Bowel Dis 2014;20:488-94.

5. Lazarev M, Huang C, Bitton A, Cho JH, Duerr RH, McGovern DP, et al. Relationship between proximal Crohn's disease location and disease behavior and surgery: a cross-sectional study of the IBD Genetics Consortium. Am J Gastroenterol 2013;108:106-12.

6. Peyrin-Biroulet L, Loftus EV Jr, Colombel JF, Sandborn WJ. The natural history of adult Crohn's disease in population-based cohorts. Am J Gastroenterol 2010;105:289-97.

7. Fielding JF, Toye DK, Beton DC, Cooke WT. Crohn's disease of the stomach and duodenum. Gut 1970;11:1001-6.

8. Gottlieb CH. Regional jejunitis. Am J Roetgenol 1937;38:881-3.

9. Wagtmans MJ, Verspaget HW, Lamers CB, van Hogezand RA. Clinical aspects of Crohn's disease of the upper gastrointestinal tract: a comparison with distal Crohn's disease. Am J Gastroenterol 1997;92:1467-71.

10. Shapiro M, Greenstein AJ, Byrn J, Corona J, Greenstein AJ, Salky $B$, et al. Surgical management and outcomes of patients with duodenal Crohn's disease. J Am Coll Surg 2008;207:36-42.

11. Nugent FW, Roy MA. Duodenal Crohn's disease: an analysis of 89 cases. Am J Gastroenterol 1989;84:249-54.

12. Gong J, Wei Y, Gu L, Li Y, Guo Z, Sun J, et al. Outcome of surgery for coloduodenal fistula in Crohn's disease. J Gastrointest Surg 2016; 20:976-84.

13. Wilk PJ, Fazio V, Turnbull RB Jr. The dilemma of Crohn's disease: ileoduodenal fistula complicating Crohn's disease. Dis Colon Rectum 1977;20:387-92.

14. Gasche C, Scholmerich J, Brynskov J, D’Haens G, Hanauer SB, Irvine EJ, et al. A simple classification of Crohn's disease: report of the Working Party for the World Congresses of Gastroenterology, Vienna 1998. Inflamm Bowel Dis 2000;6:8-15.

15. Lightner AL, Fletcher JG. Duodenal Crohn's disease: a diagnostic conundrum. J Gastrointest Surg 2018;22:761-3.

16. Dindo D, Demartines N, Clavien PA. Classification of surgical complications: a new proposal with evaluation in a cohort of 6336 patients and results of a survey. Ann Surg 2004;240:205-13.

17. Korelitz BI, Waye JD, Kreuning J, Sommers SC, Fein HD, Beeber J, et al. Crohn's disease in endoscopic biopsies of the gastric antrum and duodenum. Am J Gastroenterol 1981;76:103-9.

18. Alcantara M, Rodriguez R, Potenciano JL, Carrobles JL, Munoz C, Gomez R. Endoscopic and bioptic findings in the upper gastrointestinal tract in patients with Crohn's disease. Endoscopy 1993;25: 282-6.

19. Rutgeerts P, Onette E, Vantrappen G, Geboes K, Broeckaert L, Talloen L. Crohn's disease of the stomach and duodenum: a clinical study with emphasis on the value of endoscopy and endoscopic biopsies. Endoscopy 1980;12:288-94.

20. Diaz L, Hernandez-Oquet RE, Deshpande AR, Moshiree B. Upper gastrointestinal involvement in Crohn disease: histopathologic and endoscopic findings. South Med J 2015;108:695-700.

21. Park SH, Kim YJ, Rhee KH, Kim YH, Hong SN, Kim KH, et al. A 30 -year trend analysis in the epidemiology of inflammatory bowel disease in the Songpa-Kangdong District of Seoul, Korea in 1986-2015. J Crohns Colitis 2019;13:1410-7.

22. Limketkai BN, Shah SC, Hirano I, Bellaguarda E, Colombel JF. Epidemiology and implications of concurrent diagnosis of eosinophilic oesophagitis and IBD based on a prospective populationbased analysis. Gut 2019;68:2152-60.

23. Stjarngrim J, Ekbom A, Hammar U, Hultcrantz R, Forsberg AM. Rates and characteristics of postcolonoscopy colorectal cancer in the Swedish IBD population: what are the differences from a nonIBD population? Gut 2019;68:1588-96.

24. Bernell O, Lapidus A, Hellers G. Recurrence after colectomy in Crohn's colitis. Dis Colon Rectum 2001;44:647-54.

25. Schwartz DA, Tagarro I, Carmen Diez M, Sandborn WJ. Prevalence of fistulizing Crohn's disease in the United States: estimate from a systematic literature review attempt and population-based database analysis. Inflamm Bowel Dis 2019;25:1773-9.

26. Cottone M, Rosselli M, Orlando A, Oliva L, Puleo A, Cappello M, et al. Smoking habits and recurrence in Crohn's disease. Gastroenterology 1994;106:643-8.

27. Cosnes J, Beaugerie L, Carbonnel F, Gendre JP. Smoking cessation and the course of Crohn's disease: an intervention study. Gastroenterology 2001;120:1093-9.

28. Baek SJ, Lee KY, Song KH, Yu CS. Current status and trends in inflammatory bowel disease surgery in Korea: analysis of data in a nationwide registry. Ann Coloproctol 2018;34:299-305.

29. Sun XW, Wei J, Yang Z, Jin XX, Wan HJ, Yuan BS, et al. Clinical features and prognosis of Crohn's disease with upper gastrointestinal tract phenotype in Chinese patients. Dig Dis Sci 2019;64:3291-9. 